\title{
CONGRESSO BRASILEIRO DE DERMATOLOGIA VETERINÁRIA DA SOCIEDADE BRASILEIRA DE DERMATOLOGIA VETERINÁRIA
}

\section{A. TRABALHOS CIENTÍFICOS COM APRESENTAÇÃO ORAL}

\section{A.1. DERMATOSES ALÉRGICAS \\ 1. Estudo da sensibilidade e concordância dos testes alérgicos intradérmico e percutâneo em cães com dermatite alérgica}

\author{
Study of the sensitivity and agreement of allergic tests intradermal and \\ percutaneous in dogs with allergic dermatitis \\ BARETTA, L. T. ${ }^{1 \star}$; CUNHA, V.E.S. ${ }^{2}$; DHEIN, J.O. ${ }^{1}$; FIGUEIREDO, C.D. ${ }^{1} ;$ GERARDI, D.G. ${ }^{1}$ \\ ${ }^{1}$ Universidade Federal do Rio Grande do Sul (UFRGS), Porto Alegre, RS, Brasil \\ 2 FDA Allergenic, Rio de Janeiro, RJ, Brasil \\ ^E-mail: leticiabaretta@hotmail.com
}

Resumo: Os testes cutâneos, intradérmico (TID) e percutâneo (TP), são empregados na seleção dos alérgenos para formulação da imunoterapia alérgeno-específica em cães com dermatite atópica e ainda não se sabe o quanto os resultados obtidos nestes testes concordam entre si. 0 presente trabalho verificou se existe concordância entre os resultados positivos do TID e TP. Foram incluídos trinta cães com dermatite alérgica atendidos no setor de Dermatologia Veterinária (DERMATOVET-UFRGS) do Hospital de Clínicas Veterinárias da Universidade Federal do Rio Grande do Sul (HCV-UFRGS). 0 estudo foi realizado de forma prospectiva e aprovado pela Comissão de ética (CEUA-UFRGS, protocolo número 36746). Os testes, TID e TP, foram realizados em um mesmo momento para cada cão na lateral do tórax direito, sem contenção química. 0 mesmo investigador realizou todos os testes alérgicos e sua interpretação. Nos dois testes foram utilizados cinco extratos alergênicos: Dermatophagoides farinae (DF), Blomia tropicalis (BT), Dermatophagoides pteronyssinus (DP), Lolium multiflorum (LM), Cynodon dactylon (CD) e soluções de controle positivo e negativo fornecidos pela FDA-Allergenic Ltda (Rio de Janeiro, Brasil). As respostas foram avaliadas após 15 minutos pelos métodos subjetivo e objetivo e consideradas positivas quando reativas a pelo menos um dos métodos de avaliação. Para comparar os resultados positivos foi utilizado o coeficiente Kappa de concordância $(p<0.05)$. Quando comparados, observamos que 0 TP foi mais sensível (DF 24/30 [80\%], BT 21/30 [70\%], DP 16/30 [53,3\%], LM $3 / 30$ [10\%], CD 4/30 [13,3\%]), em relação ao TID (DF 5/30 [16,7\%], BT 14/30 [46,7\%], DP 10/30 [33,3\%], LM $0 / 30$ [0\%], CD 1/30 [3,3\%]). Houve concordância mediana entre os testes somente para o ácaro DP $(k=0,42, p=0,011)$. A concordância entre os testes para os ácaros DF $(k=0,10, p=0,221)$ e BT $(k=0,22, p=0,196)$, não foi significativa, e, para os pólens $L M$ e, CD não foi avaliável. Uma possível explicação para a fraca concordância entre os testes seria o potencial irritativo dos TIDs que, diferentemente dos TP, necessitam ser diluídos para se evitar respostas falso-positivas. Conclui-se que TID e TP podem discordar e que o TP foi mais sensível que os TID.

Palavras-chave: Testes cutâneos. Prick test. Dermatite atópica canina. Imunoterapia. Alergopatia. 


\title{
2. Lokivetmab: primeiras impressões
}

\section{Lokivetmab: first impressions}

\author{
ALBUQUERQUE, T. ${ }^{1 *}$; BEVIANI, D. ${ }^{1}$; LOPES, J. ${ }^{1}$; LUCAS, R. ${ }^{1}$; MIRANDA, V. ${ }^{1}$; PELEGRINI, C. ${ }^{1}$ \\ ${ }^{1}$ Dermatoclínica (DM), São Paulo, SP, Brasil \\ *E-mail: dra.tatianamorales@hotmail.com
}

Resumo: A dermatite atópica (DA) é uma dermatopatia alérgica de cunho hereditário com envolvimento de alérgenos. A DA canina, uma das causas mais frequentes de prurido de carácter alérgico observada nos consultórios veterinários, é uma enfermidade crônica, apenas controlável e não curável. Dentre as possíveis formas de terapia, o Lokivetmab (Cytopoint) é um anticorpo monoclonal que neutraliza a IL-31, uma citocina que desempenha um papel importante na gênese do prurido. 0 presente trabalho avaliou a eficácia do Lokivetmab para tratamento dos cães com dermatite atópica. Oitenta e seis cães receberam aplicação do Cytopoint ${ }^{\circledR}$ conforme a recomendação do fabricante com dose variando de $2-4,3 \mathrm{mg} / \mathrm{kg}$. Quanto à identificação sexual, $50(58,1 \%)$ eram fêmeas e 36 (41,9\%) machos, com idade de um a 15 anos e diferentes raças. Shih-tzu (18\%) e buldogue francês(12\%) foram as raças mais frequentes. A melhora do prurido foi alcançada em $71(82,6 \%)$ dos 86 cães. 64 (74,4\%) pacientes tiveram uma resposta satisfatória superior a $70 \%$ em relação à terapia anterior e com duração de mais de 20 dias após a primeira aplicação, 42 (48.8\%) pacientes, a despeito da importante melhora do prurido, mantiveram a lambedura podal. Um (1\%) animal apresentou urticária, 37 (43\%) cães apresentaram sintomatologia compatível com foliculite superficial; ainda assim, 74 (86\%) destes pacientes permaneceram sem prurido. Lokivetmab revelou-se eficaz e proporcionou um efeito duradouro na redução do prurido na maioria dos cães com dermatite atópica.

Palavras-chave: Lokivetmab. Dermatite atópica. Cytopoint ${ }^{\circledR}$. Efetividade. Anticorpo monoclonal.

\section{A.2. DERMATOSES AUTOIMUNES/ IMUNEMEDIADAS}

\section{Antibióticos tetraciclínicos, una alternativa terapéutica en el manejo del lupus eritematoso vesicular canino}

\author{
Tetracyclinic antibiotics, a therapeutic alternative in the management of canine \\ vesicular lupus erythematosus \\ BLANCO, A. ${ }^{1 *}$; DUARTE, M. ${ }^{1}$ \\ ${ }^{1}$ Facultad de Ciencias Veterinarias, Universidad de Buenos Aires (UBA), Buenos Aires, Argentina \\ *E-mail: mvalejandroblanco@gmail.com
}

Resumo: Se presentó a la consulta un canino Collie macho de siete años de edad con múltiples lesiones cutáneas. La evolución del cuadro era de cuatro meses sin presentar mejoría desde el inicio de la terapia. Había sido medicado con isoxazolinas (Fluralaner ${ }^{\circledR}$ ), cefalexina, enrofloxaciona, prednisolona a dosis terapéuticas sin mejoría. El paciente estaba decaído y anoréxico. La piel presentaba lesiones vesículoerosivas y costrosas, que afectaban la cara, los pabellones auriculares y sobre todo la región ventral: abdomen, ingle y el escroto. El raspaje cutáneo fue negativo y la citología reveló cocos fagocitados por neutrófilos. El hemograma y la bioquímica sanguínea fueron normales excepto un aumento de las enzimas hepáticas. La ecografía y las placas de tórax: sin particularidades. Se indico amoxicilina con acido clavulánico y se programó una biopsia en siete días. La histopatología informó un Lupus Eritematoso Vesicular. Se decidió comenzar basándonos en la recomendación bibliográfica con hidroxicloroquina a razón de 
$5 \mathrm{mg} / \mathrm{kg}$ cada 12 hs. A los 15 días el paciente desmejoro por lo cual se decidió agregar prednisolona a razón de $3 \mathrm{mg} / \mathrm{kg}$ cada 24 hs pero a los 15 días la remisión alcanzada fue parcial por los cual se decidió añadir ciclosporina y retirar paulatinamente la prednisolona. Pasados 30 días del tratamiento el paciente se encontró muy desmejorado clínicamente y sin cambios en las lesiones cutáneas por lo que fue suspensa la terapia y se utilizo tetraciclina 500 mg y niacinamida 500 mg a razón de una cápsula cada ocho horas. A los 15 días el paciente mostró una gran mejoría del cuadro clínico-dermatológico consiguiendo una completa remisión de las lesiones a los 30 días. La remisión se mantuvo después de más de seis meses de tratamiento. El lupus eritematoso vesicular canino es una enfermedad de rara presentación que afecta sobre todo a Collies y Shetland. Se describen varias terapias para intentar controlar la enfermedad entre ellas los glucocorticoides, la ciclosporina y la hidroxicloroquina. Hasta donde los autores conocen no hay reportes del uso de la tetraciclina-niacinamida (TN) para el control de esta enfermedad. En este paciente las tres drogas descriptas al principio no fueron efectivas para controlar la enfermedad, sin embargo al comenzar con TN la respuesta fue excelente y ha logrado mantener al paciente hasta la realización de este trabajo con un estado clínico- dermatológico estable y sin lesiones.

Palavras-chave: Lupus. Antibióticos. Tetraciclina-niacinamida. Autoinmune.

\title{
A.3. DERMATOSES BACTERIANAS
}

\section{Identificação e avaliação de resistência aos antimicrobianos em Staphylococcus spp. de cães com piodermite}

\author{
Identification and evaluation of antimicrobial resistance in Staphylococcus spp. of \\ dogs with pyoderma \\ CARVALHO, L.G. ${ }^{1 \star}$; ANTUNES, M.S. ${ }^{1}$; FONSECA, C. 0. ${ }^{1}$; PENNA, B. A. ${ }^{1}$; PESSET, C.M..${ }^{1} ;$ SILVA, I. T. ${ }^{1}$; \\ TEIXEIRA, I. M. ${ }^{1}$ \\ ${ }^{1}$ Universidade Federal Fluminense (UFF), Niterói, RJ, Brasil \\ *E-mail: Iuguica@oi.com.br
}

Resumo: Staphylococcus spp. importante na medicina humana e na Medicina Veterinária pode ser encontrado na pele e mucosas de animais assintomáticos, mas também pode estar relacionado a graves quadros de piodermite e otites em cães. A espécie que mais acomete os cães é S. pseudintermedius e em menor frequência, mas não menos importante, S. schleiferi. Sabendo do potencial de transmissão desses microrganismos e crescente aumento de casos de infecções por bactérias multirresistentes, há necessidade de se ter uma nova leitura sobre a saúde animal influenciando a saúde humana (conceito "One health"). 0 presente estudo caracterizou amostras de Staphylococcus spp. isoladas de cães com infecções tópicas bacterianas quanto à diversidade de espécies e perfil de suscetibilidade aos antimicrobianos. Amostras de 75 animais com piodermites e otites foram coletadas, com auxílio de swab estéril (aprovação do CEUA/UFF n. 1008). A identificação das espécies foi realizada com a técnica de espectrofotometria de massa (MALDI-TOF) e a suscetibilidade aos antimicrobianos testada pelo método de disco difusão. Foram identificadas 230 unidades formadoras de colônia, sendo 54\% Staphylococcus pseudintermedius, 28\% Staphylococcus schleiferi, 3\% Staphylococcus intermedius, 3\% Staphylococcus haemolyticus, 2\% Staphylococcus sciuri, 2\% Staphylococcus epidermidis, 2\% Staphylococcus hominis, 2\% Staphylococcus simulans, 1\% Staphylococcus aureus, 1\% Staphylococcus saprophyticus, 1\% Staphylococcus warneri e 1\% Staphylococcus delphini. 0 teste de sensibilidade aos antimicrobianos seguiu os padrões da CLSI e do Brcast. Os maiores percentuais de resistência foram com penicilina (84\%), eritromicina (38\%) e clindamicina (35\%) e os menores com rifampicina e doxiciclina (2\%). Foram identificados $26 \%$ Staphylococcus resistentes à meticilina, dos quais $53 \%$ S. pseudintermedius e $15 \%$ S. schleiferi. 0 presente estudo alerta para o cuidado 
com as escolhas empíricas no tratamento dermatológico, já que percentis elevados de resistência a antimicrobianos de primeira escolha foram identificados. Alerta-se ainda para o risco negligenciado das amostras resistentes à meticilina, especialmente MRSP. Portanto as escolhas de antimicrobianos nos tratamentos das otodermatopatias bacterianas nos cães, deve ser objeto de maior atenção, 0 teste de sensibilidade na escolha do tratamento deve ser sempre adotado.

Palavras-chave: Antimicrobianos. Cães. One health. Piodermite. Otite. Staphylococcus spp.

\title{
A.4 DERMATOZOONOSES
}

\section{Esporotricose felina: análise clínico-epidemiológica de casos atendidos na FMVZ-USP (2003-2018)}

\section{Feline sporotrichosis: clinical-epidemiological analysis of cases attended at FMVZ-USP (2003-2018)}

\author{
OLIVEIRA, M.S.B. ${ }^{1 *}$; LARSSON JUNIOR, C.E.; NITTA, C. Y. ${ }^{1}$ \\ ${ }^{1}$ Faculdade de Medicina Veterinária e Zootecnia (FMVZ), \\ Universidade de São Paulo (USP), SP, Brasil \\ *E-mail: mariana.silva66@hotmail.com
}

Resumo: A esporotricose constitui-se em micose subcutânea desencadeada por fungo dimórfico do Gênero Sporothrix. Apresenta distribuição mundial, embora de ocorrência mais frequente em regiões tropicais e subtropicais, mostrando-se endêmica na América Latina. No Brasil relatase, desde 1997, uma "hiperendemia" de esporotricose no estado do Rio de Janeiro, associada, principalmente, à transmissão zoonótica felino-humano de Sporothrix brasiliensis. Outros estados brasileiros, como Rio Grande do Sul e São Paulo, também apresentam números crescentes da enfermidade. 0 presente trabalho faz uma análise retro e prospectiva dos casos de esporotricose em felinos atendidos no Serviço de Dermatologia do Departamento de Clínica Médica (VCM) do Hospital Veterinário da Faculdade de Medicina Veterinária e Zootecnia da Universidade de São Paulo, no período de janeiro de 2003 a novembro de 2018, considerando: definição racial/raça, idade, gênero, tipo de criação e origem do animal Os dados obtidos foram submetidos à análise descritiva para obtenção da distribuição de frequência da enfermidade. Ao todo, foram avaliados 31 registros de felinos esporotricóticos. Foi constatada a maior frequência de machos $(65,5 \%, n=20)$, adultos jovens (idade média equivalente a 47,4 meses), não castrados $(71 \%, n=22)$ e com consentido livre acesso à rua $(71 \%, n=22)$. Quanto à forma clínica, $67.7 \%(n=21)$ dos felinos apresentaram a forma cutâneo localizada, enquanto 32.3\% $(n=10)$ apresentaram a forma cutâneo disseminada. Em seis ocasiões (20.7\%), foi confirmada a presença da infecção em felinos e em contactantes humanos dentre os que conviviam com gatos esporotricóticos. Detectou-se transmissão a outros felinos em três residências (10.3\%). Considerou-se, para o cálculo, número de residências equivalente a 29, já que três dos felinos avaliados conviviam em uma mesma residência. Em 16 anos, entre os interregnos de 2003-2010 (média de 0,37 casos/ano) e 2011-2018 (média de 3,5 casos/ ano), houve aumento equivalente a $933 \%$ em número de diagnósticos estabelecidos da micose no Serviço de Dermatologia. Tão somente no último triênio (2016-2018) o média anual foi de 6,7 casos /ano. 0 grande aumento em termos de casuística pode refletir o cabal e atual cenário epidemiológico, em que se destaca a transmissão zoonótica de Sporothrix brasiliensis. Frente à "hiperendemia" brasileira, ressalta-se a importância da enfermidade passar a ser de notificação obrigatória e com especial orientação veterinária à sociedade.

Palavras-chave: Esporotricose. Felino. Hiperendemia. Zoonose. 


\title{
6. Correlação entre pênfigo foliáceo e leishmaniose visceral em cães: relato de três casos
}

\author{
Correlation between pemphigus foliaceus and visceral leishmaniasis in dogs: \\ report of three cases
}

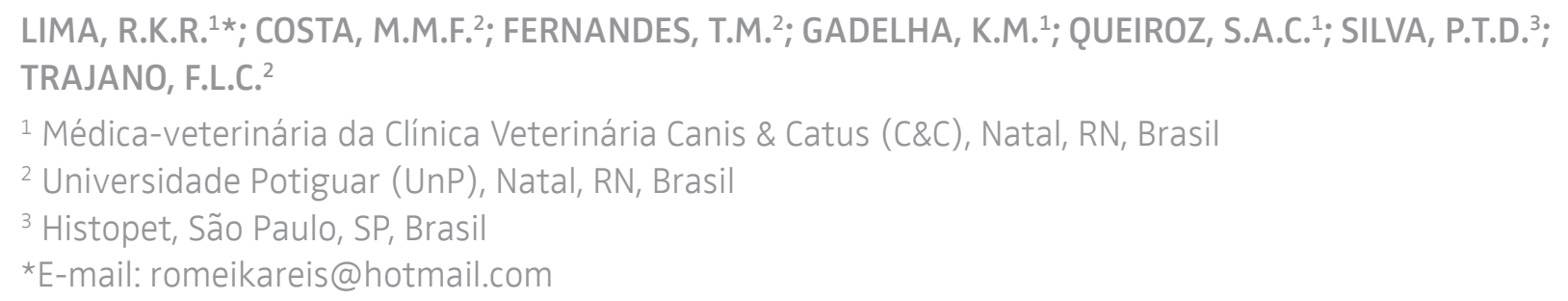

Resumo: A leishmaniose visceral canina (LVC), causada por protozoários pleomórficos do gênero Leishmania é transmitida pela picada de artrópodes entre os quais a Lutzomyia longipalpis é a espécie mais comum. As doenças autoimunes são explicadas por fatores como o fenômeno de disseminação de epítopos (epitope spreading), definido por migração do alvo de anticorpos para outros epítopos. Dentre as doenças autoimunes, o pênfigo foliáceo canino (PFC) é a mais comum, caracterizada por lesões cutâneas acantolíticas mediadas por IgG voltados a caderinas desmossômicas da epiderme. O principal alvo dos autoanticorpos é a desmocolina 1. Estudos correlacionam as semelhanças antigênicas de proteínas salivares do L. longipalpis com a desmocolina 1, podendo ser esse um forte motivo da associação LVC-PFC. Um cão Pastor Alemão (macho) e dois sem raça definida (um macho e uma fêmea), todos com idade entre dois e três anos, deram entrada em uma clínica veterinária particular do município de Natal, estado do Rio Grande do Norte, Brasil, , com lesões em ponta de orelhas, onicogrifose, descamação periocular bilateral, linfadenomegalia e alopecia generalizada, indicando manifestações suspeitas de LVC. O diagnóstico da LVC foi firmado pela determinação de títulos sorológicos elevados ou prova parasitológica. Para os três animais, a terapia foi: miltefosina ( $2 \mathrm{mg} / \mathrm{kg} / \mathrm{VO} / \mathrm{SID})$, alopurinol (10mg/kg/VO/BID), domperidona ( $1 \mathrm{mg} / \mathrm{kg} /$ $\mathrm{VO} / \mathrm{SID}$ ), prednisolona ( $1 \mathrm{mg} / \mathrm{kg} / \mathrm{VO} / \mathrm{SID}$ ) e coleira repelente à base de deltametrina. Nos machos, as manifestações clínicas mudaram de padrão após o início do tratamento, com o surgimento de pústulas generalizadas e escamas do tipo micáceas, levando à suspeita de PFC. Essas lesões ocorreram após 30 dias de terapia antiLVC no cão da raça Pastor Alemão e após 15 dias no SRD. A fêmea apresentava lesões com esse aspecto desde a primeira avaliação clínica. Na citologia, havia pústulas com numerosos neutrófilos e queratinócitos acantolíticos e ausência de bactérias. Em todos os animais, a histopatologia de pústulas íntegras confirmou o diagnóstico, demonstrando dermatite perivascular, pústula subcórnea com células acantólicas e exocitose de neutrófilos. O PFC associado à LVC gera desafio ao avaliarmos a terapia antiLVC, uma vez que as lesões dermatológicas são comuns a ambos os quadros, assim como o controle destas doenças se mostra mais difícil, já que as terapias são conflitantes. Vale salientar que a ausência de resposta clínica do ponto de vista dermatológico em pacientes com LVC pode estar associada ao surgimento de enfermidades concomitantes, destacando-se o PFC.

Palavras-chave: Pênfigo foliáceo. Disseminação de epítopos. Desmocolina. Leishmaniose. 


\title{
A.5. OTOPATIAS
}

\section{Análise retrospectiva dos casos de otite crônica em felinos avaliados por otoendoscopia em serviço de referência de otologia e dermatologia veterinária localizado na cidade do Rio de Janeiro, Brasil, em período de dois anos}

\author{
BOTELHO, C. ${ }^{1 \star}$; MARIANA, M. ${ }^{1}$ \\ ${ }^{1}$ Otoderme, Rio de Janeiro, RJ, Brasil \\ *E-mail: vetcris@gmail.com
}

Retrospective analysis of cases of chronic otitis in cats assessed by otoendoscopy over two years in an otology reference service and veterinary dermatology located in the city of Rio de Janeiro, Brazil, over two years

Resumo: A incidência de enfermidades óticas em gatos é relatada como da ordem $2 \%$ a $6 \%$,Devido a escassez de estudos nesta área, o presente trabalho investigou as principais causas de otite crônica em gatos com base em otoendoscopia (vídeo fibroscopia ótica). A análise retrospectiva trabalhou com os registros de otoendoscopias de 20 gatos com diagnóstico de otite crônica, atendidos em um período de dois anos, por serviço de dermatologia e otologia veterinária localizado na cidade do Rio de Janeiro, Brasil. As manifestações clínicas mais comuns foram otorréia, prurido ótico e meneio cefálico. Manifestações neurológicas, como "head tilt" e nistagmo, foram evidenciadas nos casos em que pólipos e otite média foram diagnosticados. Pólipos inflamatórios obstruindo o canal auditivo e neoplasia foram os diagnósticos mais comuns (cinco casos de cada - 25\%), seguidos de otite média (quatro casos, uni ou bilaterais - 20\%), otite externa ceruminosa (4 casos - 20\%), otite fúngica e um caso de otite parasitária (Demodex cati); apenas um caso de otite externa purulenta bilateral (5\%) foi observada. Sendo assim os pólipos inflamatórios e as neoplasias foram as causas primárias de otite crônica mais diagnosticadas em gatos, seguidos por otite média unilateral e bilateral. Esses achados corroboram a importância do uso de algumas técnicas avançadas de inspeção indireta para o estabelecimento de diagnóstico preciso de otite crônica em gatos.

Palavras-chave: Crônica. Felinos. Otite. Otoendoscopia.

\section{A.6. PSICODERMATOSES}

\section{Características de temperamento de cães com dermatopatias alérgicas de acordo com análise qualitativa e escala de distúrbios de comportamento}

Characteristics of temperament of dogs with skin diseases allergies according to qualitative analysis and scale of disorders of behavior

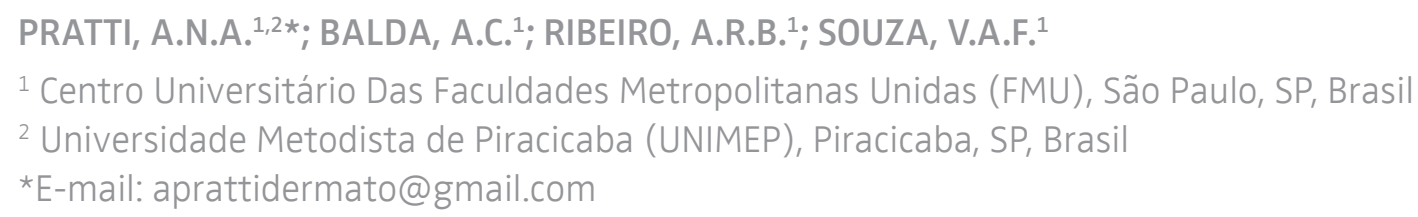

Resumo: Em Medicina Veterinária, há poucos estudos sobre aspectos emocionais vinculados as dermatopatias alérgicas. 0 presente trabalho, aprovado pelas normas do CONCEA e pela CEUA/FMU, 
sob protocolo 120330117 , utilizou a metodologia de avaliação qualitativa de comportamento (QBA - "qualitative behaviour assessment") para descrever aspectos do temperamento de cães com dermatopatias alérgicas incluindo dermatite atópica e dermatite trofoalérgica. Foram avaliados 26 cães, 16 com dermatopatias alérgicas e 10 controles sem a patologia. A análise estatística gerou dois componentes principais (PC1 e PC2), totalizando 62,4\% da variação explicada no grupo de cães alérgicos e 70,7\% no grupo controle. Foram aplicadas também as Escalas de distúrbios cognitivos e emocionais (EDED), índice CADESI 4 e grau de prurido segundo RYBNICEK. As dimensões geradas pelo QBA apresentaram os eixos sociável/feliz/confiante a nervoso/entediado/apático em PC1 e agitado/esperto/atento a frustrado/entediado/apático, em PC2. Houve correlação positiva moderada entre o escore EDED e índice CADESI $4(p<0,05)$ sugerindo que ansiedades e dermatopatias alérgicas possam ter um vínculo e que os cães alérgicos apresentaram características de temperamento associadas a menos expressões de emoções positivas. Os resultados obtidos ressaltam a importância da avaliação de características de temperamento e alterações emocionais no manejo de dermatopatias alérgicas em cães.

Palavras-chave: Avaliação qualitativa de comportamento. Bem-estar animal. Dermatite atópica canina. Temperamento.

\title{
A.7. OUTROS
}

\section{Estudo retrospectivo da casuística dos atendimentos dermatológicos em felinos em 24 meses, em hospital veterinário-escola, localizado na cidade de São Paulo, estado de São Paulo, Brasil}

\author{
Retrospective study of case series dermatitis in cats in 24 months, in hospital \\ school veterinarian, located in the city of Sao Paulo, state of Sao Paulo, Brazil \\ GONÇALVES, J.C. ${ }^{1 *}$; BALDA, A.C. ${ }^{1}$; NUNES, T.C. ${ }^{1}$ \\ ${ }^{1}$ Centro Universitário das Faculdades Metropolitanas Unidas (FMU), São Paulo, SP, Brasil \\ *E-mail: jucg.vet@gmail.com
}

Resumo: 0 presente analisou os registros retrospectivos das dermatopatias registradas em gatos atendidos no Hospital Veterinário das Faculdades Metropolitanas Unidas em um período de 24 meses. Foram atendidos 27.020 animais, dos quais os casos dermatológicos corresponderam a $1,7 \%$ de todas as consultas realizadas com gatos. O levantamento foi realizado por análise de 155 prontuários de felinos com suspeitas de dermatopatias, das quais se observou uma distribuição quase equitativa das dermatoses de quaisquer dos sexos, apenas por discreto predomínio de fêmeas (52\%). As dermatoses mais observadas foram, em ordem decrescente, a puliciose (25\%), dermatite alérgica à picada de ectoparasitas (20\%), esporotricose (10\%), sarna otodécica (9\%), dermatite atópica (6\%), complexo granuloma eosinofílico (6\%), dermatofitose (6\%), dermatite de contato (3\%), escabiose felina $(2,5 \%)$, hipersensibilidade alimentar $(2,5 \%)$, acne felina $(1,9 \%)$, criptococose (1,9\%), dermatite actínica $(0,6 \%)$ e linfoma cutâneo (0,6\%). O levantamento envolveu análise de prontuários, onde se dispunha de dados como espécie, definição racial, idade e sexo dos animais atendidos. A faixa etária entre os pacientes machos foi de 5,2 anos de idade e nas fêmeas em 7,1 anos. Em relação à raça, a maior parte dos gatos não possuía plena definição racial.

Palavras-chave: Dermatopatias. Gatos. 


\title{
B. TRABALHOS CIENTÍFICOS EM PÔSTER ELETRÔNICO
}

\section{B.1. DERMATITES FÚNGICAS E PROTECÓTICAS}

\section{Associação de itraconazol com terbinafina para tratamento de esporotricose em felino: relato de caso}

\author{
Association of itraconazole with terbinafine for the treatment of feline \\ sporotrichosis: a case report \\ SALZO, P.S. ${ }^{1 *}$; SILVA, M.B. ${ }^{1}$ \\ ${ }^{1}$ Universidade São Judas Tadeu (USJT), São Paulo, SP, Brasil \\ ^E-mail: paulosalzo@hotmail.com
}

Resumo: Na cidade de São Paulo, estado de São Paulo, Brasil, tem sido observado o aumento, ano a ano, do número de casos de esporotricose, enfermidade zoonótica, transmitida principalmente pelo gato doméstico. 0 tratamento de escolha é efetuado com o emprego do itraconazol derivado azólico que altera a permeabilidade da membrana fúngica, pela inibição da síntese do ergosterol. Uma solução supersaturada de iodeto de potássio, administrada por via oral, também pode ser utilizada em gatos; no entanto, o risco de hepatotoxicidade aumenta quando comparado ao uso de itraconazol. A terbinafina, derivado alilamínico, que interfere na biossíntese dos esteróis fúngicos, induz deficiência de ergosterol e acúmulo intracelular de esqualeno, determinando a morte da célula fúngica, tem demonstrado eficácia no tratamento da esporotricose humana e pode ser uma alternativa para o tratamento de gatos que não tolerem itraconazol, que respondam mal ou quando há suspeita de resistência aos azólicos. Dentre as combinações possíveis, a mais utilizada é itraconazol e iodeto de potássio, no entanto podem ser utilizadas combinações de itraconazol e fluconazol ou, ainda, itraconazol e terbinafina. O presente trabalho relata a eficácia da combinação itraconazol e terbinafina em um felino acometido por esporotricose. Foi atendido em uma clínica privada um felino, fêmea castrada, sem raça definida, seis anos, 3,3 kg com lesões cutâneas nodulares, ulceradas e crostosas localizadas na face. 0 tratamento inicial foi realizado com itraconazol na dose de $100 \mathrm{mg} /$ gato, pela via oral, a cada 24 horas. Quarenta e cinco dias depois o animal retornou ao atendimento com disseminação das lesões pelos membros e tronco. 0 protocolo de tratamento foi alterando com a inclusão de $10 \mathrm{mg} / \mathrm{kg}$ de iodeto de potássio, via oral, a cada 24 horas. Após 39 dias da adição do halogenado, o animal retornou ao atendimento com importante piora de estado geral (perda ponderal $300 \mathrm{~g}$ ) e presença de lesões cutâneas disseminadas. Assim, o iodeto de potássio foi retirado do protocolo de tratamento e foi adicionado terbinafina na dose de $30 \mathrm{mg} / \mathrm{kg}$, via oral, a cada 24 horas. Após 68 dias da combinação itraconazol e terbinafina, 0 animal apresentou melhora completa das lesões cutâneas e do estado geral (ganho ponderal $200 \mathrm{~g}$ no período). Tal curso clínico sugere que o felino apresentou resistência ao itraconazol e a cura clínica foi obtida com a adição de terbinafina ao protocolo de tratamento. 0 uso da combinação itraconazol e terbinafina não é usual, porém é uma alternativa possivelmente eficaz para a cura clínica da esporotricose.

Palavras-chave: Esporotricose. Felino. Itraconazol. Terbinafina. 


\title{
11. Estudo retrospectivo da ocorrência de dermatofitoses em cães e gatos na região da grande Florianópolis, estado de Santa Catarina, Brasil
}

Retrospective study of the occurrence of dermatophytosis in dogs and cats in the region of greater Florianópolis, state of Santa Catarina, Brazil

NETO, A.S. ${ }^{1 \star}$; NUNES, C.P. ${ }^{1}$

${ }^{1}$ Universidade do Sul de Santa Catarina (UNISUL), Florianópolis, SC, Brasil

*E-mail: adriano.asn@hotmail.com

Resumo: As dermatofitoses, uma das zoonoses que mais acometem adultos e crianças, é uma das dermatopatias frequentes na clínica de pequenos animais. A doença é causada por dermatófitos e os principais agentes fúngicos presentes nas infecções observadas nos animais de companhia são o Microsporum canis, M. gypseum e o Trichophyton mentagrophytes. 0 diagnóstico e o tratamento correto das dermatofitoses nos animais são essenciais para impedir a sua transmissão aos seres humanos. 0 presente trabalho avaliou o perfil epidemiológico de cães e gatos diagnosticados com dermatofitoses na região da Grande Florianópolis, estado de Santa Catarina, Brasil, compilando os registros de 1034 laudos de cultura fúngica provenientes de um laboratório da região (Vet Análises) considerando as características: espécie animal, sexo, raça, idade e espécie fúngica. A maior frequência de ocorrência foi em animais da espécie canina (75,14\%). Para a variável sexo, houve predomínio das fêmeas (53,2\% em cães e $54,1 \%$ em felinos). Os animais sem raça definida corresponderam a 20,6\% em cães e 57,2\% em gatos. Quanto aos caninos de raça definida, foi constatado: shih-tzu (13\%), yorkshire terrier $(10,7 \%)$, pug $(5,8 \%)$, labrador retriever $(4,1 \%)$, Ihasa apso $(4,1 \%)$, buldogue francês $(3,5 \%)$, pinscher $(3,1 \%)$, golden retriever $(3,0 \%)$, maltês $(3,0 \%)$ e poodle $(3,0 \%)$. Os felinos com raça definida foram: persa (31,5\%), siamês $(5,1 \%)$ e exótico (1,2\%). Por fim, em relação à idade, os animais foram divididos em três grupos ( $<1$ ano; 1 a 7 anos; $>7$ anos). Ambas as espécies apresentaram maior prevalência no grupo de 1 a 7 anos. 0 segundo grupo mais frequente em cães com idade superior a sete anos de idade e, em gatos, o grupo com idade inferior a um ano. Houve predomínio do Microsporum canis, tanto em caninos quanto em felinos (99\% em cães e 99,6\% em gatos), seguido por Microsporum gypseum $(0,8 \%)$ em cães e Trichophyton mentagrophytes (0,3\%). Já, nos felinos, a segunda espécie mais frequente foi Microsporum gypseum (0,4\%).

Palavras-chave: Dermatofitose. Cultura. Cão. Gato. Cultivo micológico.

\section{Esporotricose cutânea felina: estudo retrospectivo de um triênio em serviço de dermatologia de hospital veterinário-escola localizado na cidade de São Paulo, Brasil}

\author{
Feline cutaneous sporotrichosis: a retrospective study of a veterinary school \\ hospital dermatology service located in the city of Sao Paulo, Brazil
}
DORVALINO, M.L.R. ${ }^{1 *}$; BALDA, A.C. ${ }^{1}$; FILGUEIRA, K.D. ${ }^{1}$; GALATTI, L.H.H. ${ }^{1}$; LARSSON, C.E. ${ }^{1}$; LARSSON JUNIOR, C.E. ${ }^{1}$; LUCAS, S.R.R. ${ }^{1}$; NITTA, C.Y. ${ }^{1}$; OLIVEIRA, M.S.B. ${ }^{1}$
${ }^{1}$ Faculdade de Medicina Veterinária e Zootecnia (FMVZ), Universidade de São Paulo (USP), São Paulo, SP, Brasil ^E-mail: maria.dorvalino@usp.br

Resumo: A esporotricose, micose subcutânea ou intermediária causada por distintas espécies do gênero Sporothrix, é uma antropozoonose que pode acometer diversas espécies de animais. Os 
gatos domésticos infectados apresentam alto risco de transmissão intra e interespécie, uma vez que albergam maior quantidade de patógenos nas lesões cutâneas e ungueais, cavidades oral e nasal. Nos últimos anos a esporotricose tem sido registrada na cidade de São Paulo e cidades vizinhas o que ressalta a importância da realização de estudos de casuística. 0 presente trabalho analisou os registros dos casos de esporotricose felina, atendidos pelo Serviço de Dermatologia do Hospital Veterinário da Faculdade de Medicina Veterinária e Zootecnia da Universidade de São Paulo (São Paulo, Brasil) no período de 2016 a 2018 . Os animais com diagnóstico presuntivo de esporotricose $(n=38)$ foram distribuídos em três categorias: positivos, negativos e inconclusivos. Para os positivos as características a analisadas foram: sexo, intervalo de idade, raça e exames complementares voltados ao estabelecimento de diagnóstico etiológico. Destes 38 felinos, 18 (47\%) resultaram positivos, 15 (40\%) foram negativos e cinco (13\%) não tiveram diagnóstico concluso. Dentre os indivíduos positivos, 11 (61\%) eram machos e sete (39\%) fêmeas. Três (16\%) felinos encontravam-se na faixa etária inferior a um ano de idade, nove (50\%) na de um a três anos, cinco (28\%) entre cinco a nove anos e apenas um (6\%), idade aproximada de 20 anos. 15 (83\%) gatos não possuíam plena definição racial. Em relação às provas laboratoriais, em 14 (78\%) pacientes, o cultivo micológico possibilitou o estabelecimento do diagnóstico da enfermidade; nos demais (4/22\%), o diagnóstico foi estabelecido pelo exame citofungoscópico.

Palavras-chave: São Paulo. Esporotricose. Estudo retrospectivo. Gato.

\title{
B.2. DERMATOSES ALÉRGICAS
}

\section{Avaliação de pH cutâneo de cães da raça shih-tzu com dermatite atópica}

\author{
Skin pH evaluation of shih-tzu dogs with atopic dermatites \\ NETO, A.S. ${ }^{1 *}$; JOLY, G. S. ${ }^{1}$; RODRIGUES, E.L.; URNAU, L.F. ${ }^{1}$ \\ ${ }^{1}$ Universidade do Sul de Santa Catarina (UNISUL), Florianópolis, SC, Brasil \\ ^E-mail: adriano.asn@hotmail.com
}

Resumo: A dermatite atópica canina (DAC) é uma dermatose inflamatória que leva a uma deficiência na barreira cutânea tornando-a mais suscetível a prurido e a infecções secundárias. 0 aumento do pH cutâneo contribui para a inflamação epitelial, intensificando as alterações ocorridas na DAC. C. 0 presente trabalho aprovado pelo Comitê de Ética no Uso de Animais (CEUA) da Universidade do Sul de Santa Catarina, protocolo no 17.041.5.05.IV, avaliou os valores de pH cutâneo em 18 diferentes regiões anatômicas de cães da raça shih-tzu, diagnosticados com DAC Foram avaliados 24 cães, 14 fêmeas e 10 machos. Os cães selecionados estavam na faixa etária de um a 10 anos de idade. A mensuração dos valores de pH foi realizada com o emprego do pHmetro cutâneo portátil (modelo HI 99181, Hanna Instruments ${ }^{\circledR}$, Woonsocket, EUA), considerando os parâmetros: região do corpo, sexo e se o animal era castrado. A análise comparativa das regiões corporais de fêmeas e machos apresentou resultado médio mais alcalino para ambos os grupos na região peri labial, com pH de 7,18 nas fêmeas e 7,69 nos machos, com significância estatística $(p<0,0001)$. Na avaliação comparativa de fêmeas versus machos e castrados versus não castrados não houve diferença estatística ( $p>0,9999)$. Na comparação de locais do corpo dos animais castrados e não castrados, os valores mais elevados foram os da região peri labial, com alteração estatística significativa ( $p<0,0001$ ), e pH médio de 7,38 nos castrados e 7,43 nos não castrados. Pelos resultados obtidos, pôde-se verificar que, embora nem todos os valores de pH encontrados tenham sido alcalinos, os valores observados foram maiores que observados em estudo realizado com cães hígidos da mesma raça, na região peri labial. Outrossim, muitos valores tenderam para a alcalinidade. Também houve diferença estatística em algumas das diferentes regiões anatômicas analisadas. Desta forma não houve diferença estatística entre os cães atópicos e hígidos na maioria 
das regiões anatômicas mensuradas. Assim, não se pode afirmar que o pH de cães atópicos em "crise alérgica" tende à alcalinidade nas principais regiões lesadas.

Palavras-chave: pH tegumentar. Barreira cutânea. Cães. Dermatite atópica.

\title{
14. Avaliação do grau de atividade física e intensidade do prurido em cães com dermatite atópica tratados com prednisona
}

\author{
Assessment of the degree of physical activity and pruritus intensity in dogs with \\ atopic dermatitis treated with prednisone
}

\author{
GERARDI, D.G. ${ }^{1 \star}$; ALIEVI, M.M. ${ }^{1}$; DUARTE, R.C. ${ }^{1}$; GERARDI, A.B.T. ${ }^{1}$; LUPION, C.G.. ; SILVA, A.V. ${ }^{1}$ \\ ${ }^{1}$ Universidade Federal do Rio Grande do Sul (UFRGS), Porto Alegre, RS, Brasil \\ *E-mail: d_gerardi@hotmail.com
}

Resumo: 0 prurido é uma sensação desagradável que provoca o desejo do cão de coçar-se, morderse ou lamber-se. 0 prurido é considerado primário nas alergopatias tegumentares, como a dermatite atópica canina (DAC). A mensuração da intensidade do prurido é muito importante nos pacientes com DAC, no entanto, é um parâmetro subjetivo. Atualmente a Escala analógica visual do prurido (EAVP) tem sido empregada para determinar a gravidade de prurido na qual, por meio da percepção do tutor, é estabelecida uma pontuação, que varia de 0 a 10. Na busca de um método mais objetivo foi proposta a utilização de monitores de atividade física, conhecidos como acelerômetros. 0 presente estudo, aprovado pela Comissão de Ética no Uso de Animais da Universidade Federal do Rio Grande do Sul (UFRGS), com registro número 32202, investigou a existência de correlação entre os valores da nota da EAVP com o grau de atividade física detectado pelo acelerômetro (ActiGraph ${ }^{\circledR}$ ) em cães com DAC. Também foi avaliada a ação antipruriginosa a curto prazo do fármaco prednisona, comparado ao placebo, por meio do registro da atividade física pelo acelerômetro e nota da EAVP. Foram trabalhados 14 cães com DAC, provenientes da rotina clínica do Hospital de Clínicas Veterinárias da UFRGS. O diagnóstico de DAC foi efetuado por meio do histórico, exame físico e exclusão de outras doenças pruriginosas. Por sete dias consecutivos os pacientes utilizaram uma coleira com um acelerômetro e durante esse período os tutores forneceram uma nota diária para o prurido segundo a EAVP. De forma duplo-cego, a partir do quarto dia, os cães receberam o ativo antipruriginoso ou o placebo. Os resultados obtidos indicaram ausência de correlação entre valores do acelerômetro com a EAVP. A prednisona foi significativamente eficaz em reduzir o prurido avaliado pela EAVP, quando comparada ao placebo. No entanto, não houve diferença significativa na redução da atividade física após a administração da prednisona ou do placebo. A conclusão obtida foi que, a avaliação por meio do acelerômetro é um método complementar a EAVP e deve ser empregada em conjunto para determinação da intensidade do prurido. A prednisona foi eficaz em reduzir o prurido a curto prazo segundo a percepção do tutor.

Palavras-chave: Acelerômetro. Caninos. Prurido. Glicocorticóide. 


\title{
15. Aplicação de células tronco mesenquimais no tratamento de dermatite atópica em cães
}

\author{
Application of mesenchymal stem cells in the treatment of atopic dermatitis in dogs \\ RAMOS, F.O. ${ }^{1 \star}$; BRUNEL, H.S.S. ${ }^{1}$; CASTRO, M.B. ${ }^{1}$; LIMA, E.M.M. ${ }^{1}$; MALARD, P.F. ${ }^{1}$; PALUDO, G.R. ${ }^{1}$ \\ ${ }^{1}$ Universidade de Brasília (UnB), Brasília, DF, Brasil \\ *E-mail: fernandaramos2907@gmail.com
}

Resumo: A dermatite atópica canina (DA), uma doença genética, inflamatória, pruriginosa com interações de aeroalérgenos e trofoalérgenos, é caracterizada pela alteração da barreira cutânea, decorrente da diminuição dos lipídeos interlamelares. Foram selecionados vinte cães com diagnóstico de DA, com idade variando de um a 12 anos, peso médio 8,8kg, com Termo de Consentimento de tratamento firmado. A gravidade das manifestações clínicas foi estabelecida de acordo com CADESI-4 em grupos leve $(n=7)$, moderado $(n=7)$ e severo $(n=6)$. Nos dias 0 e 82 , os pacientes foram submetidos ao escore do CADESI-4, grau de prurido pelo escore da escala visual (VAS) e biópsia de pele. As aplicações das células-tronco mesenquimais de tecido adiposo de cães doadores (CTMS), na dose de $2 \times 10^{6} / \mathrm{kg}$, foram realizadas nos dias 10, 31 e 52. Os critérios de avaliação foram hemograma, ALT, creatinina, CADESI-4, VAS e temperatura retal. No exame histopatológico foram avaliados infiltrado inflamatório perivascular, hiperplasia da epiderme, edema superficial da derme e mensuração da espessura da epiderme. Quanto ao CADESI-4, no dia 82, grupo leve, 71,4\% score para abaixo de 10, grupo moderado, $100 \%$ indicaram score leve, grupo severo, $16,7 \%$ reduziu para grau moderado. Com relação ao grau de prurido, grupo leve, dia 0, 14,3\% extremamente severo, $71,4 \%$ severo e $14,3 \%$ moderado, no dia $82,28,6 \%$ severo, $42,9 \%$ moderado e $28,6 \%$ leve, no grupo moderado, dia $0,100 \%$ severo, dia $82,33,3 \%$ moderado e no grupo severo, dia $0,83,3 \%$ extremamente severo e $16,7 \%$ severo, dia $82,33,3 \%$ extremamente severo, $50 \%$ severo e $16,7 \%$ apresentaram grau leve. Os parâmetros hematológicos e temperatura corporal não apresentaram alterações. O histopatológico do grupo leve apontou diminuição acentuada na hiperplasia, infiltrado inflamatório e edema superficial. No grupo moderado, houve melhora com relação ao edema superficial e no infiltrado inflamatório. No grupo severo, houve diminuição do edema superficial. Foi constatada diferença significativa na espessura da epiderme para os grupos moderado e severo. Com o emprego das CTMs em cães com DA, foi verificada melhora clínica quanto ao CADESI-4, VAS, diminuição da espessura da epiderme, todos relacionados com a minimização do padrão inflamatório. A terapia com CTMs revelou-se como uma opção promissora para a atenuação da DA, constatando-se melhora do quadro clínico no período observado (D0 a D82) e ausência de efeitos colaterais.

Palavras-chave: Dermatite atópica. Cães. Célula-tronco.

\section{Detecção de sensibilização cutânea a ácaros em cães atópicos com o emprego de testes de puntura}

\author{
Detection of cutaneous sensitization to mites in atopic dogs with the use of prick tests \\ NUNES, T.A.P. ${ }^{1 *}$; CUNHA, V.E.S. ${ }^{1,2}$; ROCHA, R.F.D.B. ${ }^{1}$; SILVA, C.A.P. ${ }^{1}$ \\ ${ }^{1}$ Alergia Veterinária - Clínica Veterinária, Rio de Janeiro, RJ, Brasil \\ 2 FDA Allergenic, Rio de Janeiro, RJ, Brasil \\ *E-mail: tiagoapn@hotmail.com
}

Resumo: Testes intradérmicos (TID) são utilizados há décadas em cães com dermatite atópica (DA) para identificação de possíveis fontes de alérgenos no ambiente. Em seres humanos - devido à maior 
acurácia, praticidade e segurança, os testes de puntura (TP) substituíram os TID e o mesmo parece estar ocorrendo em Medicina Veterinária. O presente trabalho empregou a TP para investigar a sensibilização cutânea a ácaros em cães atópicos domiciliados na cidade do Rio de Janeiro, Brasil. Foram analisados, retrospectivamente, resultados de TP em 54 cães com diagnóstico clinico de DA (Critérios de Favrot) atendidos em clínica particular na cidade do Rio de Janeiro, entre janeiro de 2018 e julho de 2019. Em todos os casos foram testadas cinco espécies de ácaros encontradas frequentemente na poeira domiciliar (FDA Allergenic/Immunotech): Dermatophagoides farinae (DEF), Dermatophagoides pteronyssinus (DEP), Blomia tropicalis (BLO), putrescentiae (TYR) e Acarus siro (ACA). Todos os testes foram realizados em duplicata com "puntor" Duotipll (Multitest ${ }^{\circledR}$ ) direcionando a gota de antígeno ou solução controle em um ângulo de aproximadamente $45^{\circ}$ a $60^{\circ} \mathrm{com}$ a pele, de forma a provocar 0 rompimento da epiderme e a penetração da solução testada. As leituras dos controles e dos antígenos foram realizadas após 15 e 18 minutos, respectivamente. As respostas foram consideradas positivas quando houve a formação de pápula com diâmetro de ao menos três mm acima do diâmetro do controle negativo. Dos 54 cães testados, 37 (68,5\%) apresentaram resultados positivos a pelo menos uma espécie de ácaro, dos quais 28 (51,9\%) a DEF, 23 (42,6\%) a DEP e TYR, 20 (37\%) a BLO, e 10 $(18,5 \%)$ a ACA. Dos 37 cães com respostas positivas, apenas dois $(5,4 \%)$ estavam monosensibilizados, $16(43,2 \%)$ estavam sensibilizados a duas espécies, sete (18,9\%) a três, 11 (29,7\%) a quatro, e um $(2,7 \%)$ as cinco espécies de ácaros testadas. Os resultados obtidos indicam que osácaros da poeira domiciliar são importantes fontes de alérgenos para cães com DA na cidade do Rio de Janeiro e que na maioria das vezes os pacientes são polissensibilizados.

Palavras-chave: Alérgenos ambientais. Dermatite atópica canina. Prova alérgica cutânea.

\title{
17. Avaliação fenotípica de cães das raças Ihasa apso, pug e yorkshire terrier acometidos por dermatite atópica
}

\section{Phenotypic evaluation of dogs of the Ihasa apso, pug and yorkshire terrier affected by atopic dermatites}

\author{
SALZO, P.S. ${ }^{1 *}$; FERNANDES, A.C. ${ }^{1}$; ZANCO, N.A. ${ }^{1}$ \\ ${ }^{1}$ Universidade Metodista de São Paulo (UMESP), São Paulo, SP, Brasil \\ *E-mail: paulosalzo@hotmail.com
}

Resumo: A dermatite atópica (DA), o segundo distúrbio cutâneo alérgico mais comum em cães, pode acometer cerca de $20 \%$ dos animais. Trata-se de doença multifacetada de caráter genético e inflamatório, na qual o paciente torna-se sensibilizado a antígenos ambientais. Apresenta uma resposta imune equívoca e exacerbada e uma barreira cutânea deficiente. 0 fenótipo clínico pode ser influenciado por inúmeros fatores, incluindo a herança genética do animal, o seu modo de vida, o ambiente, a natureza dos antígenos ofensores e a fatores de risco. Algumas raças são mais predispostas à DA, tais como, Ihasa apso, yorkshire e pug, que têm grande casuística em hospitais e clínicas veterinárias, com diversas queixas de alterações no sistema ototegumentar, principalmente o prurido frequente. 0 presente trabalho analisou o padrão lesional e de prurido em Ihasas apso, yorkshires e pugs de quaisquer dos sexos, já diagnosticados anteriormente com DA, atendidos entre janeiro de 2017 a abril de 2019 no Hospital Veterinário da Universidade Metodista de São Paulo, cidade de São Paulo, Brasil procurando verificar a existência de algum aspecto fenotípico mais peculiar para cada raça. A pesquisa incluiu vinte e três cães da raça Ihasa apso, com predomínio de fêmeas (quinze fêmeas e oito machos), com idade média de seis anos, resultando maior acometimento da região interdigital (96\%), face (83\%) e orelhas (74\%) e menor da região de tronco (9\%); vinte e dois cães da raça yorkshire, com predomínio de fêmeas (treze fêmeas e oito machos), com idade média de seis anos, resultando maior acometimento da região interdigital (91\%), orelhas (77\%) e tronco (64\%) e menor das regiões perianal (9\%) e cabeça (5\%); sete cães da 
raça pug, com predomínio de machos (cinco machos e duas fêmeas), com idade média de três anos, resultando maior acometimento da região interdigital (100\%), abdômen (86\%) e orelhas (86\%) e menor acometimento das regiões cefálica (14\%) e cervical (14\%). Conclui-se que, ao se comparar o padrão fenotípico das raças estudadas, não houve grande diferença em termos de distribuição lesional, apesar da potencial diferença genética. Contudo, são necessários estudos com número maior de cães.

Palavras-chave: Dermatite atópica. Fenótipo. Lhasa apso. Pug. Yorkshire.

\title{
B.3. DERMATOSES AUTOIMUNES E IMUNOMEDIADAS
}

\section{Uso do oclacitinib associado à ciclosporina no tratamento de dermatomiosite símile em um cão: relato de caso}

\author{
Use of oclacitinib associated with cyclosporine in the treatment of simile \\ dermatomyositis in a dog: case report
}

OLIVEIRA, C. D. ${ }^{1 *}$

${ }^{1}$ UniCare Vet Especialidades Veterinárias, Campinas, SP, Brasil

^E-mail: camiladoll@hotmail.com

Resumo: A dermatopatia isquêmica canina é determinada por uma vasculopatia/vasculite, cuja etiologia pode estar associada a antígenos vacinais, a agentes infecciosos, a alimentos, a doenças imunemediadas, a fármacos, a neoplasias e à idiopatia. No tratamento da dermatopatia isquêmica são utilizados imunossupressores/imunomoduladores como: glicocorticoides, ciclosporina, pentoxifilina, azatioprina, sulfassalazina com sucesso variável. 0 presente trabalho descreve o uso de oclacitinib associado à ciclosporina em um cão da raça terrier brasileiro, macho, de 1,5 anos de idade, com lesões crônicas de mais de um ano de evolução. 0 animal com histórico de uso de múltiplas medicações prévias para o tratamento de dermatopatia "indefinida" apresentava lesões alopécicas, eritematosas em extremidades de membros, lesões erosivas em proeminências ósseas, alopecia em plano nasal e periocular, pavilhões com crostas e exulcerações. Para o diagnóstico, foi realizado teste sorológico e PCR de medula óssea para investigação de leishmaniose e biópsia para exame histopatológico. Os resultados foram negativos para leishmaniose e o resultado de histopatológico compatível com dermatomiosite (dermatite de interface e vasculite pobre em células e atrofia folicular intensa). 0 tratamento com prednisolona $1,5 \mathrm{mg} / \mathrm{kg}$ SID e pentoxifilina $10 \mathrm{mg} / \mathrm{kg}$ BID por 30 dias determinou pequena melhora, seguido da substituição da pentoxifilina pela ciclosporina $5 \mathrm{mg} / \mathrm{kg}$ SID e gradual da prednisolona. Após trinta dias de ciclosporina, foram observadas novas lesões de centro necrótico e bordas eritematosas em regiões cervical ventral, dorsocaudal, exulcerações em extremidades e pavilhões auriculares. A introdução do oclacitinib $0,4 \mathrm{mg} / \mathrm{kg}$ SID associado à ciclosporina, determinou evidente melhora no retorno de sete dias. A associação de oclacitinib e ciclosporina foi mantida por 90 dias, e o animal foi acompanhado com exames de rotina para a detecção de possíveis efeitos adversos. Aos 90 dias da associação, foi constatada significativa melhora das lesões crostosas, necróticas e exulcerativas, permanecendo apenas lesões cicatriciais e alopécicas em dorso, sendo iniciado o desmame do oclacitinib em dias alternados até os dias atuais,em que é mantido o acompanhamento para a detecção de recidivas. A rápida melhora clínica das lesões necróticas e erosivas, sugere que o oclacitinib pode ser uma opção para o tratamento das dermatopatias isquêmicas. Este efeito benéfico pode ser justificado pelo bloqueio de citocinas inflamatórias do tipo IL 2, 4, 6, 13, IL31 no receptor JACK1. A associação do oclacitinib e ciclosporina por mais que 21 dias não ocasionou efeitos adversos.

Palavras-chave: Dermatomiosite. Oclacitinib. Ciclosporina. Inflamação. Vasculopatia. 


\title{
19. Pênfigo foliáceo em caprino: relato de caso
}

\author{
Pemphigus foliaceus in goats: case report \\ SALZO, P.S. ${ }^{1 *}$; BUENO, L.M.B. ${ }^{1}$; NETO, F.T. ${ }^{1}$; NIEMAN, R.T. ${ }^{1}$; OLIVEIRA, T.M. ${ }^{1}$; XAVIER, J.G. ${ }^{2}$ \\ ${ }^{1}$ Universidade Anhanguera (UNIAN), São Paulo, SP, Brasil \\ 2 ROUS Patologia Animal, São Paulo, SP, Brasil \\ ^E-mail: paulosalzo@hotmail.com
}

Resu mo: O pênfigo foliáceo é uma enfermidade da pele autoimune crônica, observada frequentemente em cães e em menor proporção em outras espécies animais. Nos achados histopatológicos do pênfigo foliáceo, geralmente é observada acantólise subcorneal ou intragranulosa, que resulta na formação de fendas clinicamente retratadas pelo surgimento de lesões pustulares e presença de acantócitos. Nos pequenos ruminantes, os diagnósticos diferenciais do pênfigo foliáceo incluem processo alérgico agudo, piodermite, deficiência hereditária de zinco, fotodermatite e ectima contagioso. A terapia de eleição para as doenças cutâneas autoimunes é a utilização de glicocorticoides sistêmicos em doses imunossupressoras. 0 presente trabalho relata o caso clínico de uma cabra da raça alpina, fêmea, seis anos, que apresentava lesões bilaterais de pele, topograficamente simétricas com característica de formação de crostas destacáveis em região de plano nasal, periocular e pavilhão auricular associada a prurido intermitente. 0 diagnóstico baseou-se em aspectos sintomáticos, nas características das lesões tegumentares e exame histopatológico, onde se evidenciaram lesões pustulares epidérmicas, subcórneas e em camada espinhosa, com formação de coleções líquidas com população mista de leucócitos, eosinófilos e células acantolíticas, além da presença de infiltrado leucocitário misto perivascular em derme papilar com predomínio plasmocítico. A sintomatologia clínica associada aos achados macro e microscópicos foram característicos de pênfigo foliáceo. Diante disso, foi administrada dexametasona $(0.06 \mathrm{mg} / \mathrm{kg}, I M, S I D)$ durante 20 dias consecutivos. Após esse período, foi utilizado dexametasona ( $0.04 \mathrm{mg} / \mathrm{kg}, \mathrm{IM})$ a cada 48 horas, por 35 dias, seguido por mais duas semanas de aplicação, na mesma dose, porém, a cada 72 horas, até resolução completa do quadro clínico. Até a data da elaboração deste resumo, o animal encontrava-se em remissão parcial, esporadicamente apresentando recidiva, mas rapidamente respondendo ao tratamento com dexametasona. 0 pênfigo foliáceo é uma enfermidade rara em caprinos e, neste caso, o exame histopatológico foi definitivo para o diagnóstico e instituição da terapia, havendo melhora acentuada das lesões tegumentares com o tratamento utilizado.

Palavras-chave: Acantólise. Autoimune. Caprino. Pênfigo foliáceo.

\section{B.4. DERMATOSES DISQUERATINIZANTES E SEBORREICAS}

\section{Adenite sebácea em um cão da raça spitz alemão}

\author{
Sebaceous adenitis in a german spitz dog \\ MORAD, J. ${ }^{1 *}$ \\ ${ }^{1}$ Vetderme, Sorocaba, SP, Brasil \\ *E-mail: juliana@vetdermesorocaba.com.br
}

Resumo: A adenite sebácea é uma enfermidade inflamatória idiopática rara lesiva às glândulas sebáceas. Foram descritas mais de 50 raças caninas com adenite sebácea, incluindo akitas, poodles standard e samoiedas, mas não há relatos em cães da raça spitz alemão. Por outro lado, esta é uma raça que apresenta grande prevalência de Alopecia $X$, com características clínicas muito semelhantes à adenite sebácea, em que o manto piloso do animal perde a qualidade e volume, 
com a perda de pelos secundários. As modificações cutâneas variam na dependência da raça acometida e geralmente o prurido não é relatado. 0 cabal diagnóstico é estabelecido pelo exame histopatológico. 0 prognóstico é variável, dependendo da gravidade da enfermidade. Um cão da raça spitz alemão macho, de quatro anos de idade, foi atendido no consultório veterinário Vetderme, em Sorocaba - SP, apresentando rarefação pilosa em cauda, face posterior de pavilhões auriculares e região dorsal, com ausência de subpelo, pelos aglutinados "em pincel", leve disqueratinização e untuosidade em pele e pelame. 0 quadro era de evolução crônica de aproximadamente um ano. Exame parasitológico de raspado cutâneo e cultura fúngica negativos, RIFI e ELISA para leishmaniose não reagentes. No exame histopatológico de fragmento de pele da região interescapular, a epiderme apresentou hiperplasia regular leve, ortoqueratose laminar e em trançado de cesto e dilatação de óstios foliculares por hiperqueratose. $\mathrm{Na}$ derme os folículos pilosos apareceram ativos e exibiam hiperqueratose infundibular leve a moderada e completa ausência de glândulas sebáceas, em cujo local existiam infiltrados inflamatórios monomorfonucleares discretos. As glândulas apócrinas não exibiam alterações patológicas. Foi realizada coloração especial para fungos (PAS c/d) que resultou negativa. Firmado o diagnóstico de adenite sebácea crônica, instituiu-se o tratamento com banhos de imersão em extrato de calêndula $5 \%$ diluído em $200 \mathrm{ml}$ de óleo para bebês, seguido por banho com xampu desengordurante a cada quatro dias; Vitamina A 10000 UI, Ômega 3 1000mg e aplicação de spray de base aquosa manipulado com propilenoglicol $50 \%$ por todo o corpo do animal, diariamente. Observou-se início de repilação com aproximadamente 30 dias de tratamento e resolução completa dos sintomas com 90 dias. A adenite sebácea deve fazer parte do diagnóstico diferencial em cães da raça spitz alemão com suspeita de Alopecia $X$, os quais muitas vezes têm o diagnóstico pré-estabelecido apenas pelas características clínicas da doença.

Palavras-chave: Alopecia X. Glândula sebácea. Rarefação pilosa. Spitz Alemão. Seborreia.

\title{
B.5. DERMATOSES PARASITÁRIAS
}

\section{Primeiro relato de trombiculíase em cão no Brasil}

\author{
First report of thrombiculiasis in a dog in Brazil
}

\author{
SAMPAIO, R.T.B. ${ }^{1 *}$; BASSINI-SILVA, R. ${ }^{2}$; JACINAVICIUS, F.C. ; REIS, N.M.O. ${ }^{4}$ \\ ${ }^{1}$ Alvorada Pet Shop, Tatuí, SP, Brasil \\ 2 Departamento de Medicina Veterinária Preventiva e Saúde Animal, Faculdade de Medicina \\ Veterinária e Zootecnia (FMVZ), Universidade de São Paulo (USP), SP, Brasil \\ ${ }^{3}$ Laboratório Especial de Coleções Zoológicas, Instituto Butantan, São Paulo, SP, Brasil \\ ${ }^{4}$ Vetamicão - Clínica Veterinária Lavras, MG, Brasil \\ ^E-mail: rafaellatortoriello@hotmail.com
}

Resumo: As ninfas e os adultos dos ácaros trombiculídeos (Trombidiformes: Trombiculidae) são predadores de pequenos artrópodes, enquanto que as larvas são ectoparasitas de vertebrados. Durante a alimentação, as larvas liberam enzimas para digerir os tecidos epitelial e conjuntivo do hospedeiro. Neste processo, as larvas podem transmitir patógenos, bem como causar reação cutânea, caracterizada por intenso prurido associado a dermatite papular, denominada como trombiculíase. São conhecidas no mundo mais de 3700 espécies de trombiculídeos e, no Brasil, já foram listadas 69 espécies. Durante o exame de cão da raça shih-tzu, que dias antes teve acesso à mata fechada, na cidade de Juiz de Fora, estado de Minas Gerais, Brasil, foi observado prurido facial, por lesão única, pápulo-eritematosa apresentando leve disqueratinização em região periocular esquerda. Do centro da lesão foram coletados ácaros alaranjados por raspado superficial de pele. Os exemplares foram fixados em álcool etílico $98 \%$ e encaminhados para 
a Coleção Acarológica do Instituto Butantan, em São Paulo, para identificação morfológica. 0 material foi clarificado em ácido lático e montado em lâminas contendo meio de Hoyer. Após exames em microscópio com contraste de fase, os ácaros foram identificados como Eutrombicula daemoni. A única descrição desta espécie, até o momento de elaboração deste resumo, foi estabelecida em Santa Barbara do Monte Verde, também, no estado de Minas Gerais, encontrada parasitando a ave Myiozetetes similis (passeriformes). No presente estudo, reporta-se, portanto, nova identificação, em termos geográficos, do trombiculídeo Eutrombicula daemoni, em primodescrição de parasitismo canino no Brasil.

Palavras-chave: Trombiculíase. Cão. Brasil.

\section{Lynxacarus radovsky em um centro de diagnóstico parasitológico universitário: casuística de 14 anos}

\section{Lynxacarus radovsky at a diagnostic center university parasitological: 14-year-old sample}

FILGUEIRA, K.D. ${ }^{1,2 \star}$; AHID, S.M.M. ${ }^{1}$; HENRIQUE, M.P. ${ }^{2}$; LIMA, M.L.O. ${ }^{1}$; NASCIMENTO, J.0. ${ }^{1}$; PEREIRA, J.S. ${ }^{1}$

${ }^{1}$ Universidade Federal Rural do Semi-Árido (UFERSA), Mossoró, RN, Brasil

${ }^{2}$ Faculdade de Medicina Veterinária e Zootecnia (FMVZ), Universidade de São Paulo (USP), SP, Brasil *E-mail: kilderfilgueira@bol.com.br

Resumo: O Lynxacarus radovsky é um ácaro que parasita o pelame dos felinos domésticos. Apesar de ser considerado um ectoparasita insólito, por vezes a ausência de uma investigação minuciosa de sua presença pode refletir condição de subdiagnóstico. Contudo, o advento de melhorias no manejo sanitário dos gatos domésticos, como o controle populacional, limitação de acesso a ambientes externos (e consequente ausência de contato com animais errantes), além da ampla gama de ectoparasiticidas disponíveis no mercado e utilizados de modo regular, têm determinado a diminuição de ocorrência do L. radovsky na rotina da clínica dermatológica. 0 presente trabalho é uma análise retrospectiva dos registros de parasitismo de felinos por L. radovsky detectados pelo Laboratório de Parasitologia Animal da Universidade Federal Rural do Semi-Árido (Mossoró, Rio Grande do Norte, Brasil), no período compreendido entre os anos de 2005-a 2018). Compulsaram-se aspectos relacionados à quantidade de exames executados na população felina, positividade quanto à presença do ácaro, além da idade e sexo dos animais. Os registros contemplam 155 exames parasitológicos cutâneos (raspados e tricogramas) de gatos. Em sete $(4,5, \%)$ exames, foi detectado o L. radovsky. Entre os animais acometidos, dois (1,3\%) eram jovens (considerando-se até 12 meses de idade) e cinco $(3,2 \%)$ adultos, com faixa etária acima de um ano. No tocante ao sexo, três $(1,9 \%)$ eram machos e quatro (2,6\%), fêmeas. Portanto, a atenção para a presença de L. radovsky na investigação parasitológica do pelame de gatos domésticos não deve deixar de ser considerada.

Palavras-chave: "Ácaro do pelo". Estudo retrospectivo. Felis catus. 


\title{
B.6. EXAMES COMPLEMENTARES
}

\section{Avaliação do pH da pele de cães saudáveis das raças golden retriever e shih-tzu}

\author{
Skin $\mathrm{pH}$ assessment of healthy breeds of dogs golden retriever and shih-tzu \\ NETO, A.S. ${ }^{1 *}$; JOLY, G.S. ${ }^{1}$; RODRIGUES, E.L. ${ }^{1}$; URNAU, L.F. ${ }^{1}$ \\ ${ }^{1}$ Universidade do Sul de Santa Catarina (UNISUL), Florianópolis, SC, Brasil \\ *E-mail: adriano.asn@hotmail.com
}

Resumo: As dermatopatias, um dos principais quadros no atendimento clínico de cães, podem estar relacionadas ao desequilíbrio do $\mathrm{pH}$ da pele, parâmetro pouco avaliado devido à falha de acesso à equipamentos de aferição do pH. Porém, é fundamental que o médico-veterinário esteja preparado para uma correta abordagem dermatológica de cães, pois estes podem possuir o pH cutâneo mais alcalino, gerando eventuais disfunções na função da camada córnea. 0 presente trabalho, aprovado no Comitê de Ética no Uso de Animais (CEUA) com o protocolo no 17.042.5.05. IV, realizou uma tipificação dos valores normais de pH cutâneo, de regiões anatômicas de cães hígidos das raças golden retriever e shih-tzu, com o emprego do pHmetro cutâneo portátil (modelo HI 99181, Hanna Instruments ${ }^{\circledR}$. Woonsocket, EUA). Foram obtidas análises de 54 cães, 27 da raça golden retriever e 27 da raça shih-tzu, agrupados por idade e sexo.. Os animais foram agrupados segundo a faixa etária em: "filhotes" (seis meses a um ano), "adultos" (dois a seis anos) e "idosos" (acima de sete anos). 0 pH cutâneo dos golden retrievers (média e desvio padrão) segundo a região corpórea foram: Periocular $(6,40) \pm 1$; Pavilhão auricular $(6,38) \pm 1$; Peri labial $(6,50) \pm 1$; Perianal $(6,57) \pm 1$; Axilas $(6,56) \pm 1$; "Virilha" $(6,52) \pm 1$; Abdômen $(6,50) \pm 1$; Inguinal $(6,45)$ \pm 1 ; Flanco $(6,32) \pm 1$; Coxins palmares $(6,50) \pm 1$; Coxins plantares $(6,34) \pm 1$. Os valores obtidos nos cães da raça shih-tzu,foram: Periocular $(6,10) \pm 1$; Pavilhão auricular $(6,14) \pm 1$; Peri labial $(6,28) \pm 1$; Perianal $(6,32) \pm 1$; Axilas $(6,32) \pm 1$; "Virilhas" $(6,32) \pm 1$; Abdômen $(6,36) \pm 1$; Inguinal $(6,40) \pm 1$; Flanco $(6,38) \pm 1$; Coxins palmares $(6,54) \pm 1$; Coxins plantares $(6,64) \pm 1$. Não houve diferença significativa na comparação do $\mathrm{pH}$ cutâneo entre sexos, contudo, foram evidenciadas diferenças entre idades, $(\mathrm{P}<0,05)$, no $\mathrm{pH}$ de "filhotes" quando comparado aos golden retrievers "idosos" nas regiões: "virilha", abdômen, inguinal, coxins palmares e coxins plantares. Já, na raça shih-tzu, houve diferença $(P<0,05)$ entre "filhotes" e "adultos" apenas na região periocular, e entre "filhotes" e "idosos" nas regiões de: axilas, "virilhas", inguinal e flanco. Por fim, analisandose tabela com valores médios do $\mathrm{pH}$, das regiões anatômicas aferidas, segundo raça, idade e sexo, pôde-se constatar que, nas duas raças avaliadas o pH cutâneo que tende a ser mais ácido, apresenta uma alcalinização com o envelhecimento.

Palavras-chave: Aferição de pH cutâneo. Regiões anatômicas. Pele ácida. Pele alcalina. Cães. 


\title{
B.7. GENODERMATOSES
}

\section{Acrodermatite letal do bull terrier: revisão de literatura e relato de caso}

\section{Lethal acrodermatitis of the bull terrier: literature review and case report}

\author{
RIBEIRO, M.A.P. ${ }^{1 *}$; BOECHAT, L.P. ${ }^{1} ;$ CUNHA, R.A. ${ }^{1}$; FUSETTI, L.G. ${ }^{1} ;$ GARDEZANI, L.F. ${ }^{1}$; SILVA, L.C. ${ }^{1}$; \\ WERNER, J. ${ }^{2} ;$ ZORZI, C.B. ${ }^{1}$ \\ ${ }^{1}$ Fundação de Ensino Superior de Bragança Paulista (FESB), Bragança Paulista, SP, Brasil \\ ${ }^{2}$ Centro de Diagnóstico em Patologia Veterinária - Laboratório Werner \& Werner, Curitiba, PR, Brasil \\ *E-mail: marcelo.adani@gmail.com
}

Resumo: Uma fêmea canina com oito meses de idade, da raça bull terrier foi atendida pelo Setor de Dermatologia do Hospital Veterinário da Fundação de Ensino Superior de Bragança Paulista (FESB) com histórico de lesões cutâneas em face e extremidades de membros, presentes desde que os proprietários a adotaram, com apenas oito semanas de idade. Foi informado também que o animal apresentava apatia, retardo no desenvolvimento, perda de peso, dificuldade na mastigação e dor acompanhada por claudicação intermitente de todos os membros locomotores. Ao exame físico, foi constatada a presença de lesões cutâneas não pruriginosas em face (ponte nasal e região periocular), extremidade distal dos membros locomotores, interdígito e nas articulações tíbio-társicas e úmero-rádio-ulnares. As lesões caracterizavam-se por rarefação pilosa ou alopecia, eritema e presença de crostas e escamas aderentes. Os coxins plantares e palmares apresentavam-se com intensa hiperqueratose acompanhada de paroníquia e onicodistrofia. Foi realizado o exame parasitológico de raspado cutâneo, que se mostrou negativo. No entanto, ao exame citofungoscópico foram identificadas leveduras do gênero Malassezia spp. A confirmação diagnóstica foi estabelecida com a realização de histopatologia de biópsia cutânea. As alterações microscópicas mais relevantes foram epidérmicas e consistiram principalmente de paraqueratose grave com lagos serosos e presença de crostas queratoleucocitárias. Em função dos dados obtidos pelo exame dermatológico e resultado da histopatologia, estabeleceuse o diagnóstico de acrodermatite letal do bull terrier.

Palavras-chave: Acrodermatite. Canis familiaris. bull terrier.

\section{B.8. ONCODERMATOSES}

\section{Linfoma cutâneo canino: análise de um septênio}

\section{Canine cutaneous lymphoma: analysis of a septen}

FILGUEIRA, K. D. ${ }^{1,2 *}$; BEZERRA, J.A.B. ${ }^{1}$; CARDOSO, I.A.R.S. ${ }^{1}$; FERNANDES, K.S.B. R. ${ }^{1}$; RODRIGUES, R.T.G.A. ${ }^{1}$

\footnotetext{
${ }^{1}$ Universidade Federal Rural do Semiárido (UFERSA), Mossoró, RN, Brasil

2 Faculdade de Medicina Veterinária e Zootecnia (FMVZ), Universidade de São Paulo (USP), Brasil `E-mail: kilderfilgueira@bol.com.br
}

Resumo: O linfoma cutâneo, um quadro neoplásico incomum em cães, que representa $2 \%$ das neoplasias tegumentares,. caracteriza-se pela proliferação de células linfoides neoplásicas na epiderme, derme ou tecidos anexos. Com base nessa percepção o linfoma cutâneo é s 
histologicamente classificado em dois tipos: epiteliotrópico e não epiteliotrópico. Geralmente o linfoma cutâneo apresenta um mau prognóstico pois há uma menor resposta ao tratamento devido à reduzida concentração dos quimioterápicos na pele. 0 presente trabalho estabelece um perfil epidemiológico do linfoma cutâneo canino,a partir da análise retrospectiva das . fichas clínicas, do Hospital Veterinário da Universidade Federal Rural do Semiárido (Mossoró, Rio Grande do Norte, Brasil), referentes ao período compreendido entre os anos de 2011 a 2017. As características analisadas foram: sexo, idade, raça, tempo de evolução e velocidade de crescimento neoplásico, distribuição e configuração lesional, classificação histológica, tratamento, percentis de recorrência e óbitos. No período analisado houve oito cães atendidos estavam acometidos por linfoma cutâneo, dos quais cinco fêmeas e três machos; a faixa etária média foi a de oito anos; apenas um animal não possuía definição racial, sete animais) exibiam padrões raciais definidos, sendo o Poodle o de maior frequência $(n=6)$ ). 0 período evolutivo médio foi o de dois meses. A velocidade de crescimento foi "lenta" em dois casos e "rápida" nos demais ; em cinco cães, a neoplasia era localizada em contraste com a disseminação tegumentar (incluindo as junções mucocutâneas) em três pacientes. As configurações em placa e numular foram as mais frequentes (100\%), seguidas pelas serpiginosa e arciforme (50\%). Histologicamente foram detectados sete casos de linfoma não epiteliotrópico e apenas um na forma epiteliotrópica. Em três ( animais não foi empregado de qualquer tipo de terapia, mas em cinco foi estabelecida a quimioterapia antineoplásica. Nos animais submetidos a tratamento, houve recidiva da neoplasiaem todos os casos e os . oito animais vieram ao óbito.

Palavras-chave: Canis familiaris. Dermatologia. Estudo retrospectivo. Neoplasia linfoide.

\title{
B.9. OTOPATIAS
}

\section{Lagochilascaríase e pólipo inflamatório como causa de otite unilateral supurativa em felino - relato de caso}

\author{
Lagochilascariasis and inflammatory polyp as a cause of otitis unilateral \\ suppurative in feline - case report
}

\author{
CARDOSO, M.C. ${ }^{1 \star}$ \\ ${ }^{1}$ Dermalove - Dermatologia Veterinária by Mônica Cabral, Caxias do Sul, RS, Brasil \\ *E-mail: dermalove@hotmail.com
}

Resumo: A otite é uma doença inflamatória multifatorial aguda ou crônica da orelha. Em felinos a otite externa é menos frequente que em caninos. Os pólipos inflamatórios estão entre os crescimentos benignos mais comuns nos gatos e podem ter origem na tuba auditiva ou de inflamação da mucosa da orelha média. A lagochilascaríase é uma zoonose limitada ao continente americano, causada por um helminto nematódeo da família Ascarididae do gênero Lagochilascaris. O Lagochilascaris minor'é o parasita relatado em ratos, felinos, humanos e animais silvestres. A infecção ocorre com a ingestão de carne crua ou mal cozida contendo larvas do parasita encapsuladas. As larvas ingeridas eclodem no estômago e migram para porções superiores do tubo digestivo, infectando o panículo, geralmente na região cervical e os tecidos próximos, podendo ser observado em mandíbulas, seios maxilares, orelha média, orofaringe, alvéolos dentários e sistema nervoso central. A infecção é caracterizada por uma inflamação granulomatosa e formação de abscessos de onde são eliminados diferentes estágios do parasita. Na cidade de Bento Gonçalves-RS, foi encaminhado a um serviço privado de dermatologia veterinária, um paciente felino, fêmea, SRD, com aproximadamente oito anos de idade, não castrada, sem histórico clínico, apresentando otite unilateral direita supurativa, odor pútrido e algia, para lavagem ótica e fibroscopia. A paciente foi submetida a exames pré-anestésicos e exame fibroscópico, foi observada uma formação polipóide, multilobulada, que emergia em direção ao 
canal auditivo externo, prolongando-se da orelha externa em direção à orelha média. Após a remoção do pólipo por tração observaram-se vermes cilíndricos, fusiformes, de coloração branco - leitosa. Foram removidos 40 parasitas nematódeos do gênero Lagochilascaris. A hiperplasia do canal horizontal não permitiu a A visualização da orelha média. Na fibroscopia realizada na orelha esquerda, não foram evidenciadas alterações. Ohistórico clínico, não tinha o registro da duração da coexistência das afecções, contudo a, mas suspeita é de que o pólipo originado na orelha média possa ter sido causado pela infecção e inflamação decorrentes da parasitose na orelha média. A fibroscopia foi fundamental para o estabelecimento do I diagnóstico, tratamento e prognóstico.

Palavras-chave: Otite. Otite em felinos. Lagochilascaríase. Polipo. Fibroscopia.

\title{
27. Colesteatoma: da evolução clínica à confirmação diagnóstica
}

\author{
Cholesteatoma: from clinical evolution to diagnostic confirmation \\ PELEGRINI, C. ${ }^{1 \star}$; ALBUQUERQUE, T.M. ${ }^{1}$; BEVIANI, D. ${ }^{1}$; LOPES, J.D. ${ }^{1}$; LUCAS, R. ${ }^{1}$ \\ ${ }^{1}$ Dermatoclinica (DM), São Paulo, SP, Brasil \\ *E-mail: carlapelegrini@uol.com.br
}

Resumo: O colesteatoma, também denominado timpanoceratoma é um cisto epidermóide que se desenvolve na orelha média, causando uma inflamação local. É incomum nos cães; no entanto, a incidência pode ser maior do que a relatada. 0 presente trabalho é i, estudo retrospectivo dos prontuários de 20 cães com colesteatoma, atendidos na Dermatoclinica, estado de São Paulo, São Paulo, Brasilcom histórico de otite externa e/ou média, uni e/ou bilateral, eventual presença de sintomas neurológicos, com diagnóstico estabelecido em resultados de exames complementares, como otoendoscopia, tomografia ou ressonância magnética. Doze cães eram machos e oito fêmeas, com idades situadas entre um a 11 anos, as respectiva raças eram: pug $(n=11)$, bulldog francês $(n=4)$, shih-tzu $(n=2)$, yorkshire ( $n=2)$ e SRD, $(n=1)$ u. Dos 20 cães, 15 apresentavam otite externa, das quais 11 ( unilaterais e quatro bilaterais; 14 animais apresentavam sintomas neurológicos, incluindo "head tilt" em todos os casos, sete com nistagmo, três com incoordenação motora, dois com dor e paralisia facial e um com a Síndrome de Horner. Dos 20 cães, nove foram submetidos a exames de imagem, sete à tomografia e dois à ressonância magnética. A tomografia sugeriu otite média em quatro e colesteatoma em três cães. Já, a ressonância magnética aplicada em dois animais, indicou a presença de otite média em ambosa. Todos os pacientes foram submetidos à otoendoscopia, que revelou a presença de otite média (10 unilateral e 10 bilateral) na totalidade dos animais. Dos materiais colhidos da orelha média, em 19 animais o aspecto era denso e pastoso e, em um foi necrótico. 0 material foi igualmente encaminhado para histopatológico, confirmando-se a suspeita de colesteatoma nos 20 animais. Os principais achados na otoendoscopia foram: quatro cães com neoformação pedunculada no ramo horizontal da orelha, três "ausência" da membrana timpânica e um com ruptura membranácea. A miringotomia foi realizada em 16 pacientes. Portanto, conclui-se que o exame otoendoscópico seguido de biópsia/histopatológico foi fundamental para o diagnóstico precoce do colesteatoma, uma vez que os exames de imagem não confirmam a presença da enfermidade no seu estágio inicia quando a bula timpânica ainda não está totalmente dilatada ou destruída.

Palavras-chave: Cães. Colesteatoma. Diagnóstico. Otite. Otoendoscopia. 


\title{
28. Otite proliferativa necrotizante felina - relato de caso
}

\author{
Feline necrotizing proliferative otitis - case report \\ ROSA, V.M. ${ }^{1}{ }^{2 *}$; BALDISSERA, A.A. ${ }^{2}$; FARIAS, M.R. ${ }^{1}$; LUDWIG, L.A. ${ }^{3}$ \\ ${ }^{1}$ Pontifícia Universidade Católica do Paraná (PUC-PR), Curitiba, PR, Brasil \\ 2 Vale-Vet Centro Médico-veterinário, São Paulo, SP, Brasil \\ ${ }^{3}$ Centro Veterinário de Especialidades DIMEVET, Cascavel, PR, Brasil \\ *E-mail: victor.medvet@gmail.com
}

Resumo: A otite externa proliferativa necrotizante felina (OEPNF) é uma síndrome rara, caracterizada pela proliferação tecidual friável, crostas e úlceras na face côncava dos pavilhões auriculares e conduto ótico com presença de secreção purulenta e odor fétido. Sua etiologia ainda é incerta, sendo os gatos jovens mais representados. Poucos são os relatos de OEPNF no mundo, até o presente não havia sido descrita no Brasil.. 0 presente trabalho relata-se um caso de OEPNF em gata, sem raça definida, de dois anos de idade, atendida em 2015 na Clínica Vale Vet-Centro Médico-veterinário, Registro, estado de São Paulo, Brasil, apresentando secreção escura, descamação e desconforto ótico. Estabeleceu-se como diagnóstico presuntivo otoacaríase, instituindo-se terapia inicial com ceruminolítico à base de trolamina, polissorbato, cloreto de sódio, composto de fenoxietanol parabenos, alantoína, Aloe Vera, ácido lático e água purificada (Dermogen $\left.\mathrm{Oto}^{\circledR}\right)$, solução otológica à base de tiabendazol, sulfato de neomicina, dexametasona e cloridrato de lidocaína (Otodem Plus ${ }^{\circledR}$ ), associados ao uso tópico de ectoparasiticida e endoparasiticida à base de moxidectina e imidacloprida (Advocate gatos ${ }^{\circledR}$ ). Realizada reavaliação em 14 dias após 0 início do tratamento, observou-se a presença de secreção purulenta densa, crostas, tecido de coloração castanha obliterando ambos os meatos acústicos, com desconforto local. A paciente foi submetida à anestesia geral para realização de otoscopia, evidenciando-se a presença de tecido friável e acastanhado no interior dos condutos auditivos. A biópsia cutânea foi realizada e o exame histopatológico revelou: dermatite hiperplásica com paraqueratose e presença de queratinócitos necróticos em todas as camadas da epiderme. 0 tratamento foi baseado em prednisolona $2 \mathrm{mg} / \mathrm{kg} / \mathrm{SID}$ por 30 dias e redução gradual até a suspensão completa da medicação em 60 dias. Toda medicação tópica prévia foi então interrompida. O paciente apresentou boa evolução clínica com completa remissão lesional aos 40 dias de tratamento. Foi acompanhada por três anos, sem apresentar recidivas. As lesões peculiares, associadas aos achados histopatológicos e à boa resposta clínica aos imunossupressores são semelhantes a de relatos congêneres. 0 principal diagnóstico diferencial da OEPNF é o eritema multiforme devido aos achados microscópicos. Supõe-se que esta enfermidade possa estar relacionada a um padrão reacional decorrente do uso tópico de medicamentos otológicos. No caso em tela os elementos disponíveis não possibilitaram a confirmação de que $s$ as lesões tivessem surgido naturalmente ou se haviam sido induzidas por um dos ativos inicialmente usados.

Palavras-chave: Gatos. Obliteração. Proliferação. Otopatia. OEPNF. 


\title{
29. Eficácia do uso de gel ótico contendo florfenicol, terbinafina e acetato de betametasona (Osurnia ${ }^{\mathrm{TM}}$ ) pela via tópica em cães com otite externa aguda ou exacerbação aguda da otite externa recorrente no Brasil: um estudo multicêntrico
}

\author{
TADINI, B. ${ }^{1 *}$; DOUCETTE, K. ${ }^{1}$; LUCAS, R. ${ }^{2}$; RECUPERO, C. ${ }^{1}$ \\ ${ }^{1}$ Elanco Saúde Animal, São Paulo, SP, Brasil \\ 2 Dermatoclínica (DM), São Paulo, SP, Brasil \\ *E-mail: b.tadini@elanco.com
}

Effectiveness of using optical gel containing florfenicol, terbinafine and betamethasone acetate (Osurnia ${ }^{\mathrm{TM}}$ ) topically in dogs with acute otitis externa or acute exacerbation of otitis externa recurrent in Brazil: a multicenter study

Resumo: A otite externa (OE) é uma das enfermidades mais comuns na rotina clínica de cães, porém a realização dos seus protocolos de tratamento convencionais c pelos responsáveis nem sempre é fácil, o que impacta o sucesso terapêutico. O osurnia ${ }^{\mathrm{TM}}$ (Elanco Saúde Animal, EUA), uma nova opção terapêutica formulada em tubos flexíveis pré-mensurados $(1 \mathrm{~mL})$, contendo florfenicol $1 \%$, terbinafina $1 \%$ e acetato de betametasona $0,1 \%$ em veículo gel que se distribui e adere a todo o conduto auditivo, é indicado para o tratamento da OE aguda e exacerbação agudizada da otite recorrente em cães, causadas por Staphylococcus pseudointermedius, Escherichia coli, Pseudomonas aeruginosa, Streptococcus canis, Proteus mirabilis, Malassezia pachydermatis e Candida albicans. 0 trabalho avaliou a eficácia de Osurnia ${ }^{T M}$ em casos de OE bilaterais agudas e exacerbações agudas das recorrentes da rotina atendidos por 16 médicos-veterinários brasileiros, além da avaliação da experiência desses veterinários e dos responsáveis. Sessenta e nove cães foram tratados duas vezes, com uma semana de intervalo, após a limpeza dos condutos auditivos somente antes da primeira aplicação. A OE foi avaliada pelos veterinários nos Dias 0 e $28 \pm 2$ por um escore citológico qualitativo e quantitativo, e nos Dias 0 , $7 \pm 2$ e $28 \pm 2$ por um escore clínico total (ECT) compreendendo quatro manifestações clínicas (eritema, exsudato, edema e erosão/ulceração). A experiência dos veterinários e dos responsáveis pelos animais foi avaliada por questionários de satisfação preenchidos ao final do tratamento. Cinquenta e nove casos foram incluídos nos dados de análise de eficácia, de acordo com os critérios de inclusão e exclusão. A presença e a enumeração de microrganismos e neutrófilos diminuíram (respectivamente, $70-86 \%$ e 89\%) no Dia $28 \pm 2$ se comparadas ao Dia 0. Todos os parâmetros clínicos individualmente e o ECT diminuíram significativamente $(P<0,05)$ nos Dias $7 \pm 2$ e $28 \pm 2$ se comparados ao Dia 0 . Os veterinários e os responsáveis pelos animais caracterizaram a melhora das manifestações clínicas e a superioridade na facilidade do tratamento quando comparadas às terapias utilizadas previamente. Quadro de hipersensibilidade foi reportado em um cão, com resolução completa após suspensão do tratamento e suporte medicamentoso. 0 gel ótico adaptável, aplicado duas vezes, é uma valiosa opção para o tratamento da OE canina aguda e da exacerbação aguda da otopatia recorrente no Brasil, auxiliando na adesão e sucesso do tratamento, inclusive como primeira escolha.

Palavras-chave: Otite externa. Cão. Osurnia ${ }^{\mathrm{TM}}$. Gel ótico. Florfenicol. 


\title{
B.10. OUTROS
}

\section{Evolução da ocorrência de dermatopatias parasitárias fúngicas e alérgicas em cães atendidos no Serviço de Dermatologia do VCM e do Hovet-FMVZ/USP, estado de São Paulo, Brasil, nas décadas de 1990,2000 e 2010}

\author{
Evolution of the occurrence of fungal parasitic skin diseases and allergic reactions \\ in dogs treated at the VCM Dermatology Service and FMVZ / USP, state of Sao \\ Paulo, Brazil, in the decades of 1990, 2000 and 2010

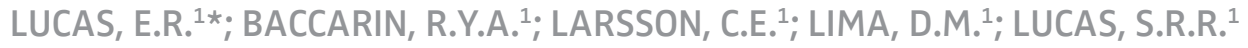 \\ ${ }^{1}$ Faculdade de Medicina Veterinária e Zootecnia (FMVZ), Universidade de São Paulo (USP), São Paulo, \\ SP, Brasil \\ *E-mail: erikarlucas@gmail.com
}

Resumo: Há duas décadas, a demanda de atendimento dermatológico na espécie canina era representada, principalmente, pelas dermatopatias parasitárias, fúngicas e alérgicas associadas à presença de ectoparasitas. Entretanto, nos últimos anos, parece ter havido uma alteração presumida na frequência de diagnóstico dessas dermatopatias 0 presente trabalho analisou a ocorrência de dermatopatias parasitárias, fúngicas e alérgicas em cães, atendidos pelo Serviço de Dermatologia do Departamento de Clínica Médica oferecido ao Hospital Veterinário da Faculdade de Medicina Veterinária e Zootecnia da Universidade de São Paulo, estado de São Paulo, Brasil e avaliou a frequência de diagnóstico dessas enfermidades ao longo dos anos. As doenças foram agrupadas inicialmente como dermatopatias alérgicas (dermatites atópica, trofoalérgica, picada de ectoparasitas e dermatopatia alérgica a esclarecer), dermatopatias parasitárias (demodiciose, escabiose e otocaríase) e as dermatopatias fúngicas (dermatofitose, criptococose e esporotricose). Foram avaliados os registros de 6.963 casos relativos aos três grupos de doenças em nove anos, correspondentes a três triênios, distribuídos ao longo de três décadas, 1995 a 1997, 2005 a 2007 e 2015 a 2017, analisados pelo método do Qui-quadrado, com nível de significância de $5 \%$. Os resultados obtidos revelaram que , as dermatites alérgicas passaram de 54,4\% dos casos na década de 1990 para 81,2\% na década de 2010, as dermatopatias parasitárias de $30,6 \%$ para $13,5 \%$ e as fúngicas de $15,0 \%$ para $5,3 \%$, com diferenças significantes $(p<0,001)$. Dentre as alérgicas, as maiores variações corresponderam à dermatite atópica (alterando-se de 4,7\% dos casos na década de 1990 para 17,0\% na década de 2010) e a dermatite alérgica a picadas de ectoparasitas, que apresentou declínio de $77,1 \%$ para $37 \%$ dos casos $(p<0,001$ ). No grupo de dermatopatias parasitárias, a demodiciose passou de 42,3\% nos anos 1990 para 24,8\% na década de 2010 e a escabiose apresentou a mesma tendência, porém com queda mais acentuada, de $45,5 \%$ dos casos nos anos 1990 para 13,0\% nos anos 2010, com diferenças significantes ( $p<0,001$ ). Com relação às dermatopatias fúngicas, persistiu o predomínio de dermatofitose, respondendo por mais de $93 \%$ dos casos desse grupo de doenças. Concluiu-se que houve alteração na casuística, com a diminuição progressiva da ocorrência de demodiciose e escabiose e dermatopatias alérgicas associadas a ectoparasitas e, finalmente, aumento dos casos de dermatopatias alérgicas não associadas a ectoparasitas.

Palavras-chave: Dermatopatias: Alérgicas. Parasitárias. Fúngicas. Cães. Casuística retrospectiva. 


\title{
31. Tratamento imunoterápico e antifúngico em cão com pitiose cutânea
}

\author{
Immunotherapy and antifungal treatment in dogs with cutaneous pythiosis \\ LIMA, C.S. ${ }^{1 *} ;$ LARSSON, C.E. ${ }^{2}$; MICHALANY, N.S. ${ }^{4}$; NITTA, C.Y. ${ }^{1} ;$ SANTANA, A.E. ${ }^{2}$; SANTOS, A.C.D. ${ }^{1 ;}$ \\ SANTOS, G.F.P. ${ }^{3}$; TABORDA, C.P. ${ }^{2}$ \\ ${ }^{1}$ Metazooa Clínica Veterinária, Santa Maria, RS, Brasil \\ ${ }^{1}$ Pitium-Vac ${ }^{\circledR}$ : imunoterápico liofilizado, Laboratório de Micologia, Universidade Federal de Santa \\ Maria (UFSM), São Paulo, SP, Brasil \\ ${ }^{2}$ Laboratório de Fungos Dimórficos Patogênicos, Instituto de Ciências Biológicas (ICB), Universidade \\ de São Paulo (USP), São Paulo, SP, Brasil \\ ${ }^{3}$ Clínica Veterinária Animed, São Paulo, SP, Brasil \\ ${ }^{4}$ Universidade Federal de São Paulo (UNIFESP), São Paulo, SP, Brasil \\ ${ }^{5}$ Faculdade de Medicina Veterinária e Zootecnia (FMVZ), Universidade de São Paulo (USP), São Paulo, \\ SP, Brasil \\ ^E-mail: crissartorato@hotmail.com
}

Resumo: Equinos, caninos, felinos e humanos são as espécies de mamíferos mais suscetíveis à pitiose. Nos cães, as manifestações tegumentares são menos corriqueiras quando comparadas aos quadros gastroentéricos. Assaz frequente em regiões tropicais e subtropicais, a enfermidade apresenta correlação importante em animais que possuem o inato hábito de nadar em lagos ou lagoas. Seu agente etiológico, Pytium insidiosum, um oomiceto, taxonomicamente descrito como um pseudo-fungo ("fungo não verdadeiro"), apresenta características biológicas peculiares, mormente, na resposta aos tratamentos antifúngicos tradicionais. Fato este, que reduz significativamente a ação da maior parte das opções terapêuticas, estimulando a busca por tratamentos alternativos como a imunoterapia, de há muito, usada com frequência e sucesso em equinos. Poucos são os trabalhos publicados relatando manifestações cutâneas em cães. A remoção cirúrgica colabora para o sucesso terapêutico, porém sua exequibilidade, dependerá da extensão, localização e cronicidade das lesões. 0 presente trabalho descreve a manifestação tegumentar da pitiose em uma cadela, com 20 kg, sem raça definida, com um ano e sete meses de idade. 0 animal residente em Araçoiaba da Serra, interior do estado de São Paulo, Brasil possuía livre acesso a lagos, cujo abastecimento hídrico provinha de rios adjacentes a inúmeras propriedades equestres. A presentava quadro dermatológico piogranulomatoso "em lençol", abrangendo região toraco-lombar bilateral, inúmeros trajetos fistulares e esfacelos, com evolução de três meses. Ao exame ultrassonográfico, evidenciou-se ausência de alterações gastroentéricas. Amostras cutâneas foram submetidas aos exames histopatológico, cultura fúngica e à reação em cadeia de polimerase, todos compatíveiscom Pytiumsp. Iniciou-setratamentocom Terbinafina $(5 \mathrm{mg} / \mathrm{kg} / \mathrm{SID}$ ) associadoao Itraconazol $(10 \mathrm{mg} / \mathrm{kg} / \mathrm{SID})$, sem melhora do padrão lesional após 30 dias. Posteriormente, instituiu-se terapia com o imunoterápico ${ }^{1}$ em doses quinzenais. Após três aplicações e com agravamento da condição geral e dermatológica, o paciente foi submetido à eutanásia. Escassos são os trabalhos que descrevem a efetividade do tratamento imunoterápico na pitiose cutânea canina. No presente relato, a introdução da imunoterapia não colaborou para o sucesso terapêutico esperado. Entretanto, deve-se ponderar que a gravidade das lesões, devido à extensão e à cronicidade, possa ter prejudicado a obtenção de melhores resultados.

Palavras-chave: Brasil. Imunoterapia. Pitiose tegumentar. Pseudofúngicas. Oomiceto. 